\title{
Dynamic Screw Systems without Image Intensifier: Early Observations in Eight Consecutive Patients
}

\author{
Ikpeme A. Ikpeme ${ }^{1}$, IniAbasi U. Ilori' ${ }^{2}$ Anthony M. Udosen ${ }^{1}$ \\ ${ }^{1}$ Department of Orthopaedics \& Trauma, University of Calabar Teaching Hospital, Calabar, Nigeria; ${ }^{2}$ Department of \\ Anaesthesia, University of Calabar Teaching Hospital, Calabar, Nigeria
}

\begin{abstract}
Citation: Ikpeme IA, llori IU, Udosen AM. Dynamic Screw Systems without Image Intensifier: Early Observations in Eight Consecutive Patients. Maced Med Sci. 2013 Mar 15;6(1):44-49. http://dx.doi.org/10.3889/MJMS.1857-5773.2013.0278. Key words: Dynamic Hip screw; Dynamic condylar screw; image intensifier; fracture care; resourcechallenged setting.

"Correspondence: Ikpeme A. Ikpeme. GPO Box 1506, Calabar, Cross River State, Nigeria. Phone: 234-803 880 9075. E-mail: iaikpeme@yahoo.com

Received: 26-Dec-2012; Revised: 27-Jan-2013; Accepted: 04-Feb-2013; Online first: 23-Feb-2013 Copyright: () 2013 Ikpeme IA. This is an openaccess article distributed under the terms of the Cretive articions Atribution Creative Commons Atribution License, which perits un in and author and source are credited. provided th

Competing Interests: The author have declared
\end{abstract} that no competing interests exist.

\begin{abstract}
Dynamic Screw Systems are useful in proximal and distal femoral fractures, and convey advantages over fixed angle devices. Improved proximal fragment fixation, controlled fracture impaction and a "forgiveness" with respect to axial alignment of the side plate to bone are improvements over fixed angle devices. Image intensifiers are often required to aid lag screw alignment when these devices are used. The equipments are expensive and often not available in some regions of the developing world. There is also the risk of radiation exposure to the surgical team.

The burden of musculoskeletal trauma is enormous in the developing world and treatment outcomes are influenced by a host of factors. The choice of the best treatment options for patients in these resource-poor regions remains a challenge. Improvisations that aid appropriate treatment while conveying documented advantages is key to patient care in musculoskeletal disease in these regions.

We document our experience in a small cohort of patients who accepted treatment of their fractures with Dynamic Screw devices in a setting without image intensifiers. Technical advances and modifications that reduce the cost of fracture care have the potential of reducing the overall cost of care in the developing world and may offer universal benefits.
\end{abstract}

\section{Introduction}

Dynamic screw systems comprising the Dynamic Hip Screw (DHS) and Dynamic Condylar Screw (DCS) were designed for use in proximal and distal femoral fractures [1]. Dynamic screw systems find use in intertrochanteric fractures except the reverse obliquity type [2], subtrochanteric fractures, supracondylar fractures of the distal femur with or without intercondylar/intra-articular components. The documented advantages of these implants over fixed angle blade plate devices include resistance to fatigue (stress) fracture and "forgiveness" in terms of axial alignment of the side plates to the femoral shaft. They also permit controlled fracture impaction which provides bone-on-bone contact with promotion of fracture union. Other advantages are improved proximal fragment fixation with the large threaded lag screws and decreased risk of screw cut out [1,2].

Image intensifiers are often desired to guide centering of the guide pin and subsequently, the lag screw in the femoral neck and head. They also permit appropriate selection of lag screw length and determination of adequate fracture reduction prior to implant insertion. Image intensifiers are however expensive and not readily available in many resources-poor centres. They also pose the risk of radiation exposure to patients and the surgical team [3]. For these reasons, external jig aided techniques are becoming increasingly popular for fracture management in resource challenged settings [4-8].

The burden of musculoskeletal trauma is enormous in the developing world. Treatment 
outcomes are influenced by a host of factors including availability of equipment, prolonged time to presentation, injudicious interventions prior to presentation in health facilities, economic challenges as well as availability of trained personnel in these regions. Surgeons working in these parts are often faced with severe injuries against the background of limited armamentarium. The challenge therefore is to decide on the best treatment option for patients under these circumstances. Improvisations, innovative thinking and an understanding of the relevant anatomy are useful adjuncts in the absence of expensive and hi-tech devices.

The AO/ASIF Group classifies proximal femoral fractures (denoted with the number 31) into 3 broad types, which are then subdivided into groups and subgroups. Trochanteric area fractures (31A) are divided into simple pertrochanteric (A1), pertrochanteric multi-fragmentary (A2) and intertrochanteric (A3). Femoral neck fractures (31B) are divided into subcapital with slight displacement (B1), transcervical (B2) and subcapital, non impacted and displaced (B3). Head fractures (31C) are divided into split fractures (C1), depressed fractures (C2) and head fractures associated with neck fractures (C3). We use the DHS in $31 \mathrm{~A} 1$ and $\mathrm{A} 2$ fractures and use the DCS in the proximal femur in $31 \mathrm{~A} 3$ and subtrochanteric fractures. We do not use the dynamic screw systems in 31B fractures because the femoral head may rotate during reaming and avascular necrosis may result.

Distal femoral fractures (33) are classified into extra-articular (33A), partial articular (33B) and complete articular (33C). Sub classification into subgroups is based on morphologic complexities (comminution), difficulties in treatment and prognosis. We commonly use the dynamic condylar screw in 33A, 33B1.1, 33B1.2 and 33C fractures. Inter fragmentary lag screws and bonegraft augmentations are used as indicated.

In our hospital, we have used dynamic screw and plate devices in the treatment of stable and unstable intertrochanteric, subtrochanteric and distal femoral fractures. Open reduction, identification of entry points and attention to the normal orientation of the bony regions help guide screw placement in the absence of an image intensifier. This article reports our early experience with the use of these devices in a resource challenged setting without image intensifiers. The authors are not aware of a previous report of this technique. Improvements and refinements in technique may ultimately help popularize this method especially in resource poor regions.

\section{Patients and Techniques}

Eight patients with fractures of the proximal and distal femur amenable to dynamic screw fixation, and who accepted the procedure were recruited in a prospective study over two years. Six patients had proximal femoral (inter- and subtrochanteric) fractures while 2 patients had distal femoral fractures with intraarticular extensions. In the proximal femur, intertrochanteric fractures were treated with the Dynamic Hip Screw (DHS). Subtrochanteric fractures and all distal femoral fractures were treated with the Dynamic Condylar Screw (DCS).

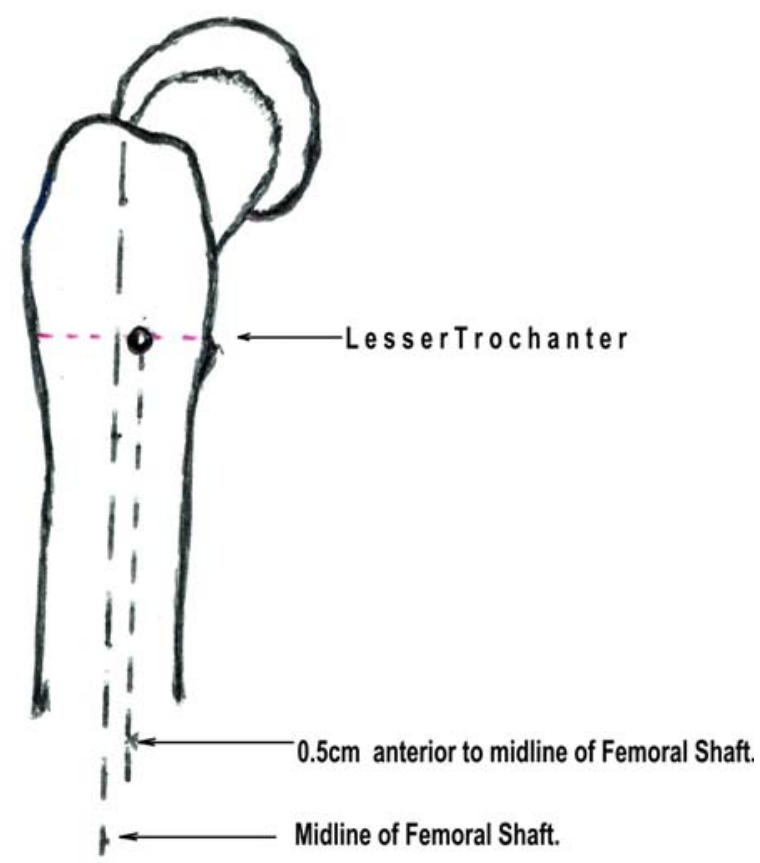

Figure 1: DHS entry point in the proximal femur.

All patients had open reduction and preliminary stabilization of their fractures under epidural anaesthesia which also permits postoperative pain control. The Lag screw lengths were pre-determined by pre-operative x-rays of the contralateral (non-fractured) lower limb region. A $10 \%$ magnification factor was deducted from the length measured on Anteroposterior x-rays and the length corrected to the nearest whole numbers less $10 \mathrm{~mm}$. For instance, if the distance measured from the lateral femoral cortex through the neck to the outer cortex of

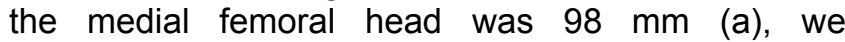
calculated and deducted $10 \%$ [9.8 $\mathrm{mm}(\mathrm{b})]$ from this value and then deducted another $10 \mathrm{~mm}$ from the answer to obtain the Lag screw length $(a-b-10 \mathrm{~mm}$ = screw length). For a measured distance of $98 \mathrm{~mm}$, the estimated Lag screw length will be $98-9.8-10=$ $78.2 \mathrm{~mm}$. We then corrected this estimated length to the nearest lower whole number available for Lag screw sizes, in this case $75 \mathrm{~mm}$. The principles of this clinical method of determining lengths are commonly used in our setting $[4,7]$.

The key to correct implant positioning within the femoral neck is the exposure and direct visualization of the neck during open reduction. This permits an evaluation of the femoral neck anterversion. A stout Kirschner wire is placed on the anterior surface of the neck in its long axis and at the junction between the superior $2 / 3$ rds and inferior $1 / 3$ rd 
and driven lightly into the femoral head to help define the direction of the neck accurately. The DHS guide pin and threaded lag screw will be inserted following the direction of this stout pin.

For DHS, the entry point is at a point $0.5 \mathrm{~cm}$ anterior to the midline of the femoral shaft on the lateral aspect of a line running circumferentially at the middle of the lesser Trochanter (Fig. 1). From the entry point, the DHS threaded guide pin is driven into the femoral neck with the aid of the $135^{\circ}$ DHS angle guide in parallel alignment with the stout pin that is used to define the femoral neck direction. When the surgeon is satisfied with the position of the threaded guide pin by visual inspection and finger palpation around the femoral neck, the DHS triple reamer is placed over the DHS threaded guide pin and the tract for the DHS lag screw is cut.

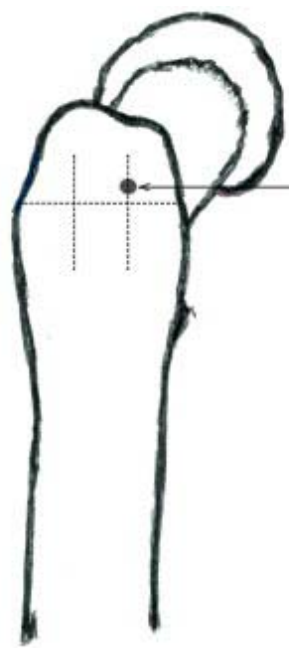

Entry Point

(0.5-1cm above the junction between

the flare of the greater trochanter and

the femoral shaft at the meeting point of

the anterior and middle thirds

(i.e. at the meeting point of the anterior

$1 / 3 r d$ and posterior $2 / 3 r d s$ ) of the greater trochanter

Figure 2: DCS entry point in the proximal femur.

When the DCS is used in the proximal femur, at least 2 stout Kirschner wires are required on the surface of the neck. The first wire is positioned as described for DHS above and driven into the femoral head. The $2^{\text {nd }}$ pin determines the definitive lag screw direction and is positioned with the aid of the condylar blade guide which subtends an angle of $85^{\circ}$. The condylar blade guide is aligned against the lateral cortex of the proximal femur and moved until it lies exactly closely, and following the matching contours of the greater trochanter and condylar plate guide. The $2^{\text {nd }}$ stout wire is then positioned exactly parallel with the superior border of the condylar guide and driven lightly into the femoral head. (One simple trick we use to achieve this is to move the condylar guide anteriorly so that it projects slightly beyond the anterior surface of the bone, place the stout wire on the superior surface of the condylar guide and drive it into the femoral head). When positioned correctly, both stout Kirschner wires subtend an angle of about $40^{\circ}$ with each other. This can be ascertained by visual estimation. The entry point when the DCS is used in the proximal femur is 0.5 to $1 \mathrm{~cm}$ just above the junction between the flare of the greater trochanter and the femoral shaft at the meeting point of the anterior and middle thirds (i.e. at the junction between the anterior $1 / 3^{\text {rd }}$ and posterior $2 / 3$ rds of the greater trochanter) (Fig. 2). The DHS/DCS threaded guide pin is inserted at this entry point and aligned exactly parallel with the $2^{\text {nd }}$ stout wire on the surface of the neck. The DCS tipple reamer is then placed over the threaded pin and the path for the DCS lag screw is cut.

Traditional descriptions of the entry point for the DHS and DCS insist on their placement in the midline of the neck. Image intensifiers guide direction of the guide pin and lag screw to lie exactly central within the femoral neck in the anterposterior and lateral views. We consider it more important that the lag screw is fully covered by bone in the neck of the femur than in its exact centralization in the absence of image intensifier guidance. For this reason, from the suggested entry points, we direct our guide pin and lag screw with a $5^{\circ}$ tilt towards the posterior portion of the head of femur. This brings the screw to lie fully covered within bone. Excessive angulation in the anterior or posterior directions will lead to malpositioning and anterior or posterior screw cut-out respectively. Finger palpation around the femoral neck should confirm that the initial guide pin and subsequent lag screw is fully covered within the neck of the femur with no anterior or posterior cut-out of the screw. Our X-rays show the outcome of this technique.

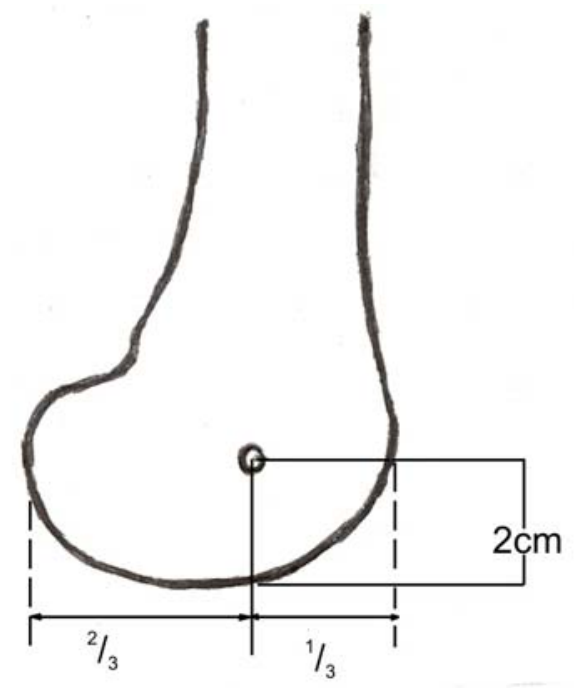

Figure 3: DCS entry point in distal femur.

In the distal femur, the DCS entry point is at the junction between the posterior two-thirds and anterior one-third of the lateral condyle at a point $2 \mathrm{~cm}$ from the distal end of the condyle (Fig. 3). Stout pins are also used to define the direction of slope of the distal femur. The condylar blade guide is placed against the lateral side of the distal femur to match the contours of the bone. The DCS threaded guide pin is them driven into the bone in parallel alignment with the pin that defines the slope of the distal femur. Because the condyles appear as posterior additions to the distal femur and the greater trochanter flares out from the upper femoral shaft, location of entry points 
for the DCS at the junction between anterior $1 / 3 \mathrm{rd}$ and posterior $2 / 3$ rds proximally and distally permit cover of the lag screw within bone even without image intensifier guidance.

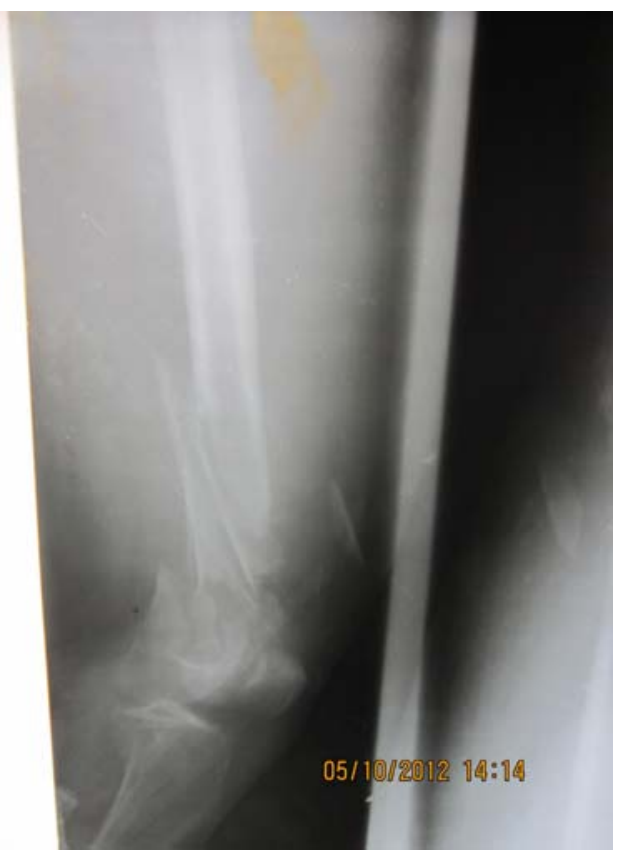

Figure 4: Pre-operative xray showing severely comminuted and unstable distal femoral fracture with an intercondylar component.

Out of the 8 patients in this small series, 5 patients had fractures which were severely comminuted and unstable (Fig. 4) while 3 patients had stable fractures. Preliminary stabilization was facilitated by the use of Kirschner wires. Once the entry points had been identified, application of the DHS or DCS followed the technical steps outlined in the AO manual of internal fixation [1]. Results were analysed using SPSS Version 20.

\section{Results}

There were 5 male and 3 female patients $(\mathrm{M}: \mathrm{F}=1.7: 1)$ aged between 23 and 90 years (Mean $55 \pm 22.57$ years). Six fractures $(75 \%)$ were located in the proximal femur (4 intertrochanteric $(50 \%)$ and 2 subtrochanteric fractures $(25 \%))$; and $2(25 \%)$ were distal femoral fractures. Five of the fractures (63\%) were severely comminuted and unstable (Fig. 4) while 3 fractures $(37 \%)$ were adjudged stable.

The Dynamic Hip Screw (DHS) was used in 4 fractures (intertrochanteric) while the Dynamic Condylar Screw was used in 4 (2 subtrochanteric and 2 distal femoral fractures). Patients were mobilized on non weight bearing crutches by the 2nd post-operative day and all wounds healed without infection. The postoperative X-rays showed satisfactory implant placement in all fractures (Fig. 5). We defined technical failure as positioning of the lag screw outside the bone in both proximal and distal fractures. Patients were discharged home on the 7 th post- operative day on bilateral non-weight bearing crutches. Ten to 12 weeks post-operatively, x-rays showed good healing with stable constructs (Fig. 2 \& 4).

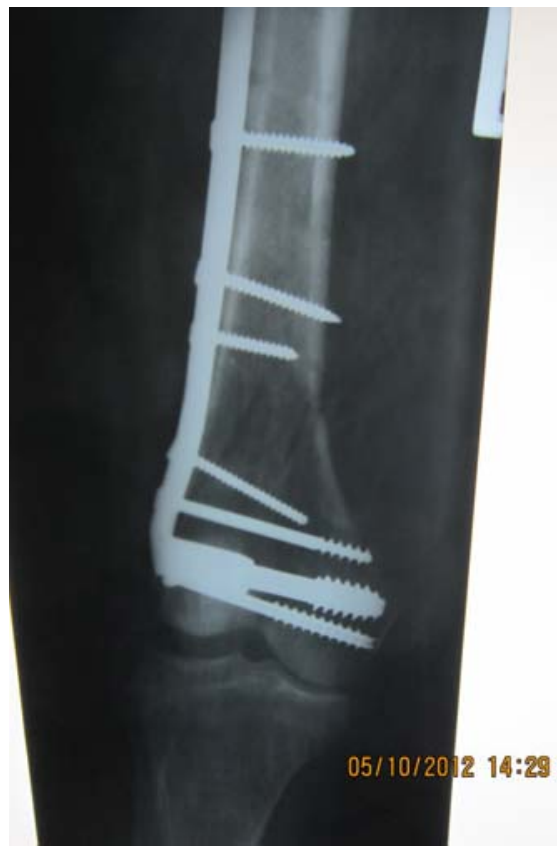

Figure 5: Immediate post-operative xray of a patient with comminuted and intercondylar fracture of the distal femur.

At an average 12 months follow-up, six of the 8 patients $(75 \%)$ had satisfactorily healed fractures with no abnormalities of gait, one patient had an impacted union (from early unauthorized full weight bearing) with mild shortening, while one patient died from causes unrelated to the fracture or surgery. Seven $(88 \%)$ out of the 8 fractures resulted from high velocity vehicular accidents while one fracture $(12 \%)$ was a pathological fracture following a low velocity fall at home. The mean duration of presentation was 3 days (72 hrs) while mean time to surgery was 7 days.

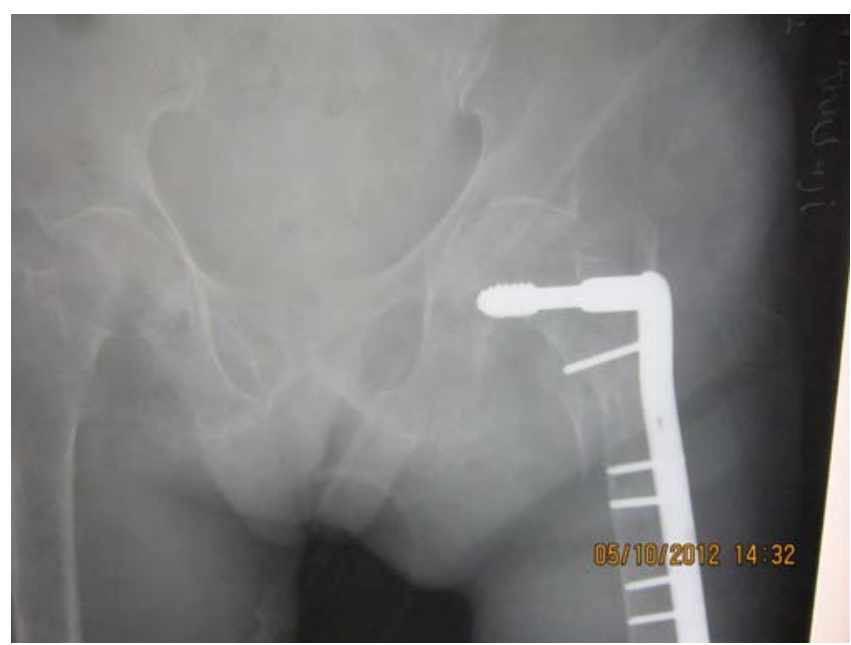

Figure 6: Immediate post-operative $X$-ray of a comminuted sub trochanteric fracture of the femur with implant in situ.

\section{Discussion}


Dynamic screw devices are versatile implants which allow for stabilization of complex unstable proximal and distal femoral fractures with excellent results [8]. These fractures would otherwise present significant challenges when fixed angle devices are used. Conservative management of such fractures with casts and traction especially in the distal femur yield unacceptably high complication events including deep vein thrombosis, urinary and pulmonary tract infections, pressure sores, non unions, pin tract infections and malunions [9-11]. Dynamic screw devices permit early joint mobilization and controlled impaction. Their "unpopularity" in resource challenged regions because of the lack of image intensifiers therefore presents surgeons with a significant choice dilemma between fixed angle devices, with the challenges of insertion and potential for non-union following non impaction of the fracture, and cast/ traction immobilization with the increased risk for joint stiffness, delayed mobilization and other complications.

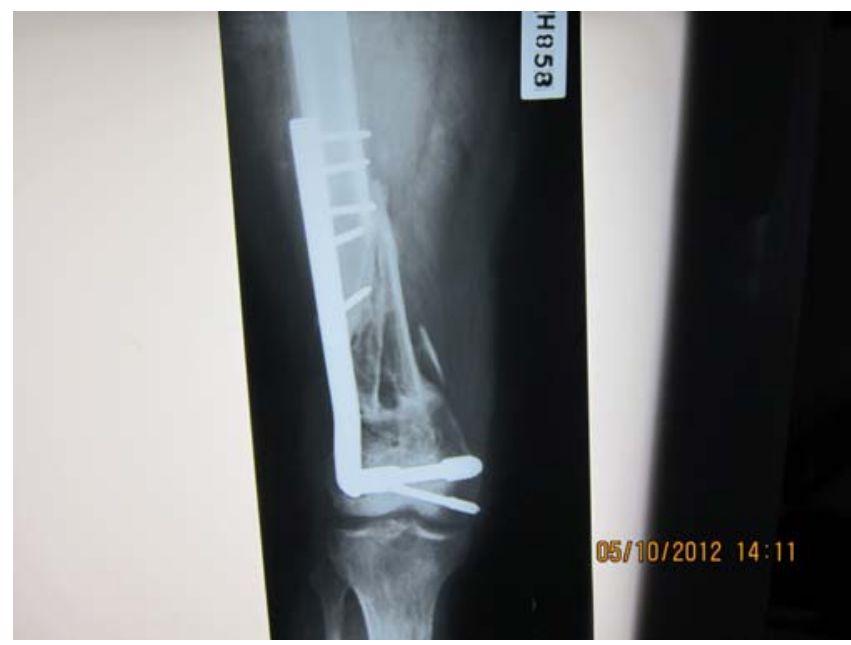

Figure 7: 12 month post-operative $X$-ray of the fracture in Figure 4 The fracture has united and patient was bearing weight without complications.

The use of external jigs in place of image intensifiers in osteosynthesis with the documented advantages of reduced cost and elimination of radiation risk to the operating team is well documented $[3-5,12]$. Their role in fracture care in the developing world has also been established [4, 6, 8]. The challenges of suboptimal trauma care in the developing world extends beyond the complications of those injuries to include the socio-economic costs of treating those complications, loss of man hours and loss of economic power among the injured who are often the economic anchor-sheets of their families and may have sustained the injuries in the course of economic pursuits. Suboptimal care therefore fuels the cycle of poverty in these resource-challenged regions. Surgeons and other health personel working in these circumstances therefore face the challenge of intervening to break the cycle of poverty by offering safe and efficacious care using relatively cheap and efficient alternatives. Improvisations and adaptations are the key to achieving these aims.

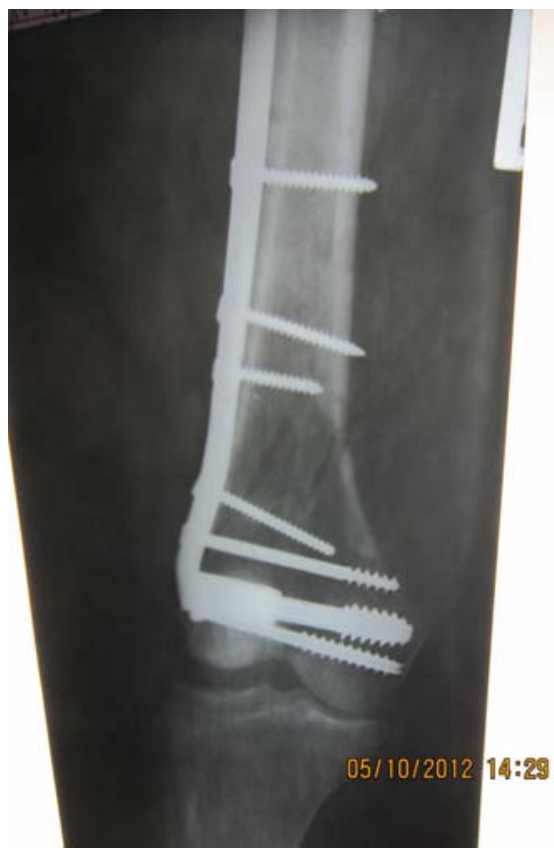

Figure 8: $10^{\text {th }}$ week post-operative $X$-ray of the fracture in Figure 5.

Our results in this small series show that with adjustments to the entry points, careful pre-operative planning and an understanding of the local anatomy, dynamic screw devices can be safely applied without the use of image intensifiers even in severely comminuted fractures. There were no incidents of lag screw cut- out and no infections in these patients. Between the DHS and DCS, it was easier to insert the DCS in the distal femur, followed by insertion of the DCS in the proximal femur for subtrochanteric fractures. Insertion of the DHS was more technically demanding. All patients in this series were treated by the same surgical team. There was a demonstrable reduction in operating time as the series progressed. A learning curve in external jig-aided osteosynthesis has previously been documented [4].

There were more men in this series and more fractures resulted from high velocity vehicular injuries. This is the typical picture seen in other literature on these fractures $[8,9]$. There were also more proximal femoral fractures with intertrochanteric fractures being the predominant pattern. Unstable fracture patterns were the majority and reflect the magnitude of forces that caused the injuries.

The optimal timing of surgical intervention for fractures remains controversial especially in multitrauma situations and the elderly. Early surgical stabilization, including damage control surgery however has documented advantages and is the norm in Western societies [12-16]. Early surgical stabilization fosters easier and more accurate reduction with the tendency for better healing, and improved outcomes; decreases the rates of ARDS, fat embolism syndrome, multiple organ failure and late 
sepsis, and the incidence of other fracture related complications. It also decreases the overall length of hospitalization and cost of medical care $[8,17]$.

Late presentation is still a major problem in the developing world but is not the only identified determinant of outcomes in musculoskeletal trauma in these societies $[18,19]$.

The mean duration of presentation in our series was 3 days and mean time to surgery was 7 days. These compare favourably with other reports from the developing world [20]. Delays in surgical intervention times were due to institutional challenges with different specialist operating teams competing for surgical space and other resources. Our long term results however compare favourably with other studies with union achieved in $87.5 \%$ of our patients within 10-12 weeks [8, 20-22]; and no recorded chronic osteomyelitis. This would suggest that appropriate intervention (including appropriate implant choices) and attention to surgical principles would produce satisfactory results in osteosynthesis even in situations of delayed presentation, delayed intervention times and improvisations/modifications of technique as may often be necessary in resourcechallenged societies.

Dynamic screw devices are versatile implants that find use in fractures where fixed angle devices will present therapeutic challenges. Their "forgiving" nature and ability to promote controlled impaction are obvious advantages. Image intensifiers remain a useful adjunct in the use of these devices. However, the outcomes in this series will suggest that they can still be safely implanted and convey the documented advantages of their design even in the absence of an image intensifier. Refinements in technique are possible and will ensure wider applicability of these devices in the developing world. In the long run, with the challenges of the global economy, technical advances that reduce the cost of fracture care will offer universal benefits in trauma science.

\section{References}

1. Müller $M E$, Allgower $M$, Schneider $R$, Willenegger $H$. (Eds) The Dynamic Hip Screw (DHS) and Dynamic Condylar Screw (DCS). In: Manual of Internal Fixation (Techniques recommended by the AO-ASIF Group). $3^{\text {rd }}$ Edition, SpringerVerlag: Berlin, 1995:270-281.

2. Buchloz RW, Heckman JD, Court-Brown CM (Eds) Intertrochanteric Fractures. In: Rockwood \& Green's fractures in Adults. $6^{\text {th }}$ Edition, Lippincott Williams \& Wilkins: Philadelphia 2006:1794-1852.

3. Giordano BD, Ryder S, Baumhauer, DiGiovanni BF. Exposure to direct and scatter radiation with use of mini-c-arm fluoroscopy. J Bone Joint Surg (Am). 2007;89:948-952.

4. Ikpeme IA, Ngim N, Udosen A, Onuba O, Oku O, Bello S. External jig-aided intramedullary interlocking nailing of diaphyseal fractures: experience from a tropical developing centre. Int Orthop (SICOT). 2011;35:107 - 111.

5. Gosselin RA, Heilto M, Zirkle L. Cost effectiveness of replacing skeletal traction by interlocked intrameduallry nailing for femoral shaft fractures in a provincial trauma hospital in Cambodia. Int Orthop. 2009;33(5): 1445-1448.

6. Feibel RJ, Zirkle LG. Use of interlocking intramedullary Tibial Nails in Developing countries. Techniques Ortho. 2009; 24(4): 233-246.

7. Ogbemudia AO, Enemudo R, Edanwonyi E. Closed interlocked nailing of a fractured femur without X-Ray Guide in First Trimester Pregnancy: A Case report. The Internet J Third World Med. 2007;5(2).

8. Sekimpi $P$, Okike $K$, Zirkle L, Jawa A. Femoral fractures fixation in developing countries: an evaluation of the surgical implant generation network (SIGN) intramedullary nail. J Bone Joint Surg. 2011; 93(19): 1811-1818.

9. Sidhu AS, Mann HS, Sidhu GDS, Bassi A. Banga A. Management of distal femur fracture - Supracondylar nailing versus open dynamic condylar screw. $\mathrm{Pb}$ Journal of Orthopaedics. 2011;12(1):22-26.

10. Streubel PN, Ricci WM, Wong A, Gardner MJ. Mortality after distal femur fractures in elderly patients. Clin Orthop Relat Res. 2011;469(4):1188 - 96.

11. Crist BD, Della Rocca G J, Murtha YM. Treatment of Acute Distal Femur Fractures. Orthopaedics. 2008; 31(7):681.

12. Butt MS, Krikler SJ, Ali MS. Displaced Fractures of the distal femur in elderly patients. Operative versus non-operative treatment. J Bone Joint Surg Br. 1996;78(1):110-114.

13. Pape HC, Tornetta P 3rd, Tarkin I, Tzioupis C, Sabeson V, Olson SA. Timing of fracture fixation in multitrauma patients: the role of early total care and damage control surgery. J Am Acad Orthop Surg. 2009;17(9):541-9.

14. Smektala R, Endres HG, Dasch B, Maier C, Trampisch HJ, Bonnaire $F$, Pientka $L$. The effect of time-to-surgery on outcome in elderly patients with proximal femoral fractures. BMC Musculoskeletal Disorders. 2008; 9:171.

15. Parker MJ, Pryor GA. The timing of surgery for proximal femoral fractures. J Bone Joint Surg Br. 1992;74(2):203-5

16. Pape HC, Hildebrand F, Pertschy S. Zelle B, Garapati R, Grimme K, Krettek C, Reed RL 2nd. Changes in the management of femoral shaft fractures in polytrauma patients: from early total care to damage control orthopaedic surgery. $J$ Trauma. 2002; 53(3); $452-461$.

17. Librero J, Peiró S, Leutscher E, Merlo J, Bernal - Delgado E, Ridao M, Martinez-Lizaga N, Sanfélix-Giméno G. Timing of Surgery for hip fracture and in-hospital mortality: a retrospective population-based cohort study in the Spanish National Health System. BMC Health Services Research. 2012;12:15.

18. O' Brien PJ. Fracture fixation in patients having multiple injuries. Can J Surg. 2003;46(2):124 - 128

19. Eke N. (Editorial). Late Presentation begs for a solution. Port Harcourt Med J. 2007; 1:75.

20. Segbefia M, Howard A. Acute Septic Arthritis and Osteomyelitis in Children - An African Perspective. 2010.

21. Jabshetty $A B$. Management of inter- trochanteric fracture by DHS fixation. Indian J Sci and Technology. 2011; 4(12):1681 1684

22. Laghari MA, Makhdoom A, Pahore MK, Memon A, Memon F A. Subtrochanteric Femoral Fractures Treated by fixation with Dynamic Condylar Screw System. JLUMHS. 2011;10(3):134 137

23. Hakeem A, Khan NU, Khan MI, Ullah F. Dynamic Condylar Screw (DCS) Fixation in treatment of supracondylar fracture of distal femur. Rawal Medical Journal. 2010;35 (1), 45 - 47. 